\title{
Testing the Modigliani-Miller theorem directly in the lab
}

\author{
M. Vittoria Levati · Jianying Qiu • \\ Prashanth Mahagaonkar
}

Received: 17 June 2009 / Accepted: 11 April 2012 / Published online: 24 April 2012

(C) The Author(s) 2012. This article is published with open access at Springerlink.com

\begin{abstract}
We present an experiment designed to test the Modigliani-Miller theorem. Applying a general equilibrium approach and not allowing for arbitrage among firms with different capital structures, we find that, in accordance with the theorem, participants well recognize changes in the systematic risk of equity associated with increasing leverage and, accordingly, demand higher rate of return. Yet, this adjustment is not perfect: subjects underestimate the systematic risk of low-leveraged equity whereas they overestimate the systematic risk of high-leveraged equity, resulting in a U-shaped cost of capital. A (control) individual decision-making experiment, eliciting several points on individual demand and supply curves for shares, provides some support for the theorem.
\end{abstract}

We would like to thank Werner Güth, Rene Levinsky, Birendra Kumar Rai, Ondrej Rydval, and Christoph Vanberg for their helpful comments and suggestions.

Electronic supplementary material The online version of this article

(doi:10.1007/s10683-012-9322-z) contains supplementary material, which is available to authorized users.

M.V. Levati

Strategic Interaction Group, Max Planck Institute of Economics, Kahlaische Strasse 10, 07745 Jena, Germany

M.V. Levati

Department of Economics, University of Verona, Via dell'Artigliere 19, 37129 Verona, Italy

J. Qiu (凶)

Department of Economics, Radboud University Nijmegen, 6525GD Nijmegen, The Netherlands e-mail: j.qiu@fm.ru.nl

P. Mahagaonkar

Entrepreneurship, Growth and Public Policy Group, Max Planck Institute of Economics, 07745 Jena, Germany 
Keywords Modigliani-Miller theorem - Experiments - Decision making under risk · General equilibrium

JEL Classification G32 $\cdot$ C91 - G12 $\cdot$ D53

\section{Introduction}

Modigliani and Miller (1958) demonstrate that in a perfect capital market ${ }^{1}$ the value of a firm is independent of how that firm is financed. Since its appearance this theorem (now known as the Modigliani-Miller or MM theorem) has been an object of lively debates and extensive empirical analyses. The original article itself includes a section devoted to testing the propositions on oil and electricity utility industries. The results show that there is little evidence of a relationship between leverage and the cost of capital. In a follow-up study, Miller and Modigliani (1966) adopt a two-stage instrumental variable procedure to estimate the cost of capital for a sample of large US electric utilities for the years 1954, 1956, and 1957. They find no evidence for "sizable leverage or dividend effects of the kind assumed in much of the traditional literature of finance".

The opposition to the MM theorem comes from many angles. Weston (1963) tests the theorem using the same sample of electricity utility industries as used by Modigliani and Miller (1958), but for the year 1959 rather than for the years 1947 and 1948. His multiple regression analysis indicates that leverage does have an influence on a firm's cost of capital when earnings growth is taken into account. Robichek et al. (1967) extend the analysis of Miller and Modigliani (1966) to the years 1955 and 1958-1964. They conclude that MM's results are a consequence of circumstances prevailing at the time of their study. Davenport (1971) uses data on three industry groups (chemicals, food, and metal manufacturing), and his results are indicative of a U-shaped cost of capital with respect to leverage. Other empirical studies suggesting that a firm's value changes significantly in response to changes in the capital structure include Masulis (1980), Dann (1981), Masulis and Korwar (1986), Pinegar and Lease (1986), Graham and Harvey (2001), and Arzac and Glosten (2005). These studies and, generally, most of the works rejecting the propositions of the MM theorem rely on some kind of market imperfections. However, no study so far has tried to focus on the more fundamental question: could the empirical violations of the MM theorem be inherent in the valuation process?

A clean and conclusive test of the above fundamental question using real market data is virtually impossible. Not only the restrictions and assumptions that the theorem demands may not be fulfilled in the real world, but also the ceteris paribus conditions, necessary to explore the impact of the debt-equity ratio on the firm's value in isolation, are often violated. Hence, an apparent significant correlation between leverage and cost of capital may be accounted for by the presence of imperfections such as taxes or transactions costs. By the same token, the seemingly independence of the

\footnotetext{
${ }^{1}$ That is, a market where there are no taxes, transactions costs, or asymmetric information, and investors and firms are price takers.
} 
capital structure from the leverage ratio may be due to a relationship between leverage and other factors influencing the cost of capital, e.g., earnings growth may offset the effect of leverage on the cost of capital (see, e.g., Weston 1963). Myers (2001, p. 86) rightly admits that the MM theorem "is exceptionally difficult to test directly". Unambiguous experimental evidence of the theorem seems therefore much-needed before we can be confident about the impact of the capital structure on the firm's value.

Motivated by these considerations, in this paper we test the MM theorem directly in a competitive market experiment. Creating a laboratory environment as close as possible to the theoretical model, we want to assess whether subjects' valuations of firms that generate the same income stream vary with the capital structure. The model we use is adapted from that of Stiglitz (1969). Using a general equilibrium approach, we prove rigorously that if individuals can borrow at the same market rate of interest as firms and there is no bankruptcy, the MM theorem always holds in equilibrium, and this result does not depend on individuals' risk attitudes and initial wealth positions. To test a key assumption of our model, we also run a (control) individual decisionmaking experiment.

Our paper contributes to the literature in at least three ways. First, we provide empirical data to test the MM theorem. Although the theorem plays a central role in corporate finance, its empirical investigation has been rather limited. Second, we examine the MM theorem in a clean and robust environment. The robustness and external validity of laboratory experimental results are often questioned due to the usually used subject pool. Since our general equilibrium approach imposes mild assumptions on individual risk attitudes and initial wealth positions, we believe that our results should hold in relatively broad conditions. Finally, we test expected utility theory in a market mechanism. Numerous studies have shown that individuals violate expected utility theory more often than otherwise. But, to our knowledge, no study has examined the theory via market mechanisms. It has been contended that markets, via arbitrage and learning, can perform better than individuals. Our finding, that the MM theorem does not hold perfectly, suggests that more work will have to be done before this contention can actually be embraced.

The paper proceeds as follows. Details about the MM theorem and our adaptation of Stiglitz's (1969) model are presented in Sect. 2, after discussing the U-shaped cost of capital approach. The experimental design is laid out in Sect. 3. The results are reported in Sect. 4. Section 5 concludes.

\section{Theories of the cost of capital}

Before 1958 the cost of capital was thought to possess a $U$ shape. The argument runs as follows. Since equity is more risky (and thus more costly) than debt, ${ }^{2}$ a firm can

\footnotetext{
${ }^{2} \mathrm{~A}$ firm promises to make contractual payments whatever its earnings. Thus, when there is no bankruptcy, debt has no risk. When there is a positive probability of bankruptcy, debt is still the less risky option because it has priority over equity in payment.
} 
reduce its cost of capital by issuing debt in exchange for equity. As the debt-equity ratio of the leveraged firm increases further, default risk becomes larger and, after some point, debt becomes more expensive than equity.

To clarify the issue, consider a firm with market value of bonds $B$ and market value of equity or shares $S$, so that $V \equiv B+S$ is the market value of the firm. Denote by $\tau=\frac{B}{V}$ the leverage ratio, by $i$ the expected rate of return on equity, and by $r$ the rate of return on debts. The unit cost of capital, $\rho$, is simply the weighted average of $i$ and $r$ :

$$
\begin{aligned}
\rho & =\frac{S}{V} i+\frac{B}{V} r \\
& =(1-\tau) \cdot i+\tau \cdot r .
\end{aligned}
$$

Two conditions are required for (1) to be U-shaped. First, $r$ must be a function of $\tau$; more specifically, $r<i$ when $\tau$ is small and $r>i$ when $\tau$ exceeds a threshold. Second, $i$ must be independent of $\tau$. As we will show below, the latter requirement does not hold if investors are risk averse.

Consider the following simple framework, which borrows heavily from our experimental setup. In time 1 (before interest payment), a firm generates income $\tilde{X}$ which can be either 1200 or 800 , with equal probabilities. The firm's expected value is therefore $\bar{X}=1000$. Suppose first that the firm is entirely financed with equity, and $V=S=600$. Then the rate of return on equity can be 2 or 1.33 , each with probability 0.5 . Hence, the expected rate of return on equity $(i)$ is 1.67 . Suppose now that the firm issues bonds $\left(B^{\prime}\right)$ worth 100 at an interest rate $(r)$ of 1.5 . By assumption $i$ remains unchanged, implying that

$$
\frac{1200-100 \times 1.5}{S^{\prime}} 0.5+\frac{800-100 \times 1.5}{S^{\prime}} 0.5=1.67,
$$

where $S^{\prime}$ is the new value of equity. Solving (2) for $S^{\prime}$ yields $S^{\prime} \approx 509$, so that the new market value of the firm is $V^{\prime}=B^{\prime}+S^{\prime} \approx 609$. The rate of return on equity is now 2.06 or 1.28 , each with probability 0.5 . Investors ask therefore for the same rate of return for an income flow with higher risk. As suggested by standard financial theory, this cannot happen if investors are risk averse.

The above example has already revealed the intuition of the MM theorem. Recognizing the relationship between $\tau$ and $i$, Modigliani and Miller's (1958) Proposition I asserts that the market value of any firm is independent of its capital structure and is given by capitalizing its expected return at some rate $\rho$ appropriate to its risk level.

\subsection{The methodology}

Several approaches may be taken to examine the MM theorem. In this paper, we shall ask experimental subjects to evaluate the equity of firms with different capital structures separately over different markets. In other words, we place each firm in a separate market, thereby excluding arbitrage among the firms. 
Arbitrage plays an important role in Modigliani and Miller's (1958) analysis for it helps to restore the stated equalities if Proposition I is violated. However, arbitrage is not necessary for the theorem to hold (see, e.g., Hirshleifer 1966; Stiglitz 1969). Additionally, allowing for arbitrage among firms may conceal the existence of preferences for firms with a particular capital structure because a few arbitrageurs could help eliminate this 'anomaly' at the market level. After all, as shown by Shleifer and Vishny (1997), arbitrage can never be complete in real financial markets. By excluding arbitrage among firms we can address a question of fundamental importance to the valuation of firms: Do subjects systematically evaluate firms with different capital structures differently? If so, how?

There is an additional strength in proceeding this way. Some empirical studies show that firms with different capital structures are evaluated similarly. Yet, this does not necessarily imply the irrelevance of capital structure to the value of the firm. The same result could be obtained if investors, in general, preferred some capital structure $\tau^{*}$ to some other capital structure $\tau^{\prime}$, but these preferences were recognized by the firms that adjusted their capital structure towards $\tau^{*}$. In this case, firms would be evaluated similarly simply because their capital structure is concentrated on $\tau^{*}$. Our approach allows us to explore this possibility.

Note, however, that the exclusion of arbitrage may cause a potential problem. Since the law of one price cannot be applied, ${ }^{3}$ the investors' personal traits (like risk attitudes or wealth levels) become relevant and can affect results. For example, the valuation of different risky shares may differ depending on the portfolio that investors hold. Yet, this difference in valuations does not reflect the difference in shares per se, but it relates to the composition of the investors' portfolio. Since we want to focus on the valuation process per se, we need to minimize the impact of the participants' own traits. For this purpose, we adopt Stiglitz's (1969) general equilibrium model. In this model the MM theorem holds regardless of the participants' initial wealth conditions. Furthermore, the equilibrium solution is derived from the state-preference approach (Hirshleifer 1966) which, compared to the more familiar mean-variance approach, does not make strong assumptions about risk attitudes or utility function shapes. Hence the results hold under more general conditions.

\subsection{The model}

Consider an economy with one firm and a set $N$ of individual investors. The firm operates for two periods: $t_{0}$ (present) and $t_{1}$ (future). The uncertain income stream $\tilde{X}$ generated by the firm at $t_{1}$ is a function of the future state of the world $\theta$. Let $\tilde{X}(\theta)$ denote the firm's income in state $\theta$. Each investor $j \in N$ is endowed with an initial wealth $\omega^{j}$, which is composed of a fraction $\alpha^{j}$ of $S$ (the firm's equity) and $B^{j}$ units of bonds. Since the economy is closed, we have

$$
\sum_{j \in N} \alpha^{j}=1, \quad \sum_{j \in N} B^{j}=B,
$$

\footnotetext{
${ }^{3}$ The law of one price states that in an efficient market all identical goods must have only one price.
} 
where $B$ stands, as before, for the market value of the firm's bonds. By convention, one unit of bond costs one unit of money. Thus, investor $j$ 's budget constraint $(\forall j \in N)$ is

$$
\omega^{j}=\alpha^{j} S+B^{j} .
$$

In addition, there exists a credit market where both the firm and the investors can borrow and lend at the rate of interest $r$. To be consistent with the assumptions of MM theorem, we suppose that the firm never goes bankrupt. Investors prefer more to less, and evaluate alternative portfolios in terms of the income stream they generate, i.e., investors' preferences are not state dependent.

\subsubsection{The benchmark solution}

In this section we shall prove the following proposition:

\section{Proposition 1}

(1) If there exists a general equilibrium with a fully-equity financed firm having a particular value, then there exists another general equilibrium solution for the economy with the firm having any other capital structure but with its value unchanged.

(2) Moreover, the property that the firm's value is unchanged holds in any equilibrium. ${ }^{4}$

Let us now consider two economies. The firm in the first economy is only financed by equity. The firm in the second economy is financed by both equity and bonds. Let $V_{1}$ and $V_{2}$ denote the value of the firm in the first and second economy, respectively. We first show that there exists a general equilibrium solution with $V_{2}=V_{1}$.

Start from the first economy. Since the firm issues no bonds, we have $V_{1}=S_{1}$ (with $S_{1}$ being the value of the firm's equity in this economy) and $\sum_{j \in N} B_{1}^{j}=0$. Here a positive (negative) value of $B_{1}^{j}$ would mean that investor $j$ invests (borrows) $B_{1}^{j}$ units of money in (from) the credit market. Let $Y_{1}^{j}(\theta)$ stand for investor $j$ 's income in state $\theta$ of economy 1 . With a portfolio consisting of $\alpha^{j}$ shares of the firm and $B_{1}^{j}$ units of bonds, investor $j$ 's return in state $\theta$ can be written as:

$$
\begin{aligned}
Y_{1}^{j}(\theta) & =\alpha^{j} \tilde{X}(\theta)+r B_{1}^{j} \\
& =\alpha^{j} \tilde{X}(\theta)+r\left(\omega^{j}-\alpha^{j} V_{1}\right),
\end{aligned}
$$

which follows from (3) and $S_{1}=V_{1}$.

Turn now to the second economy where the firm issues bonds with a market value of $B_{2}$. If $S_{2}$ denotes the value of the firm's equity in this economy, we have $V_{2}=$ $S_{2}+B_{2}$ and $\sum_{j \in N} B_{2}^{j}=B_{2}$. Notice that the firm generates the same pattern of income stream $\tilde{X}$. With a portfolio consisting of $\alpha^{j}$ shares of the firm and $B_{2}^{j}$ units of

\footnotetext{
${ }^{4}$ Stiglitz (1969) only proves the first part of the proposition. We complete the proof by demonstrating the second part. 
bonds, investor $j$ 's return in state $\theta$ is then given by:

$$
\begin{aligned}
Y_{2}^{j}(\theta) & =\alpha^{j}\left(\tilde{X}(\theta)-r B_{2}\right)+r B_{2}^{j} \\
& =\alpha^{j}\left(\tilde{X}(\theta)-r B_{2}\right)+r\left(\omega^{j}-\alpha^{j} S_{2}\right) \\
& =\alpha^{j} \tilde{X}(\theta)+r\left(\omega^{j}-\alpha^{j} V_{2}\right),
\end{aligned}
$$

where the third equality follows from $S_{2}=V_{2}-B_{2}$.

If $V_{1}=V_{2}=V^{*}$, the opportunity sets described by (4) and (5) are identical, i.e.:

$$
Y_{1}^{j}(\theta)=Y_{2}^{j}(\theta) \quad \forall \theta \text { and } \forall j .
$$

Thus, if $\alpha^{j}$ maximizes individual $j$ 's utility in the first economy, it still does in the second economy. This proves the first part of Proposition $1 .^{5}$ It remains to show that $V_{1}=V_{2}=V^{*}$ holds in any equilibrium.

Suppose that in the second economy, in addition to the equilibrium in which $V_{1}=V_{2}=V^{*}$, another equilibrium where $V_{2}^{\prime}>V_{1}=V^{*}$ exists. This in turn implies $S_{2}^{\prime}=V_{2}^{\prime}-B_{2}>V^{*}-B_{2}=S_{2}^{*}$. As the rate of return on equity is $\frac{\tilde{X}-r B}{S}$, with $\tilde{X}$ and $B$ unchanged, the increase in the firm's equity value (from $S_{2}^{*}$ to $S_{2}^{\prime}$ ) yields a decrease in the rate of return on equity. Such a decrease discourages the demand for equity in the second economy. Note that, since $V_{1}=V_{2}=V^{*}$ is supported in an equilibrium, the equity market of the second economy must be able to clear at $S_{2}^{*}=V^{*}-B_{2}$. It follows that, when the firm's equity value in the second economy increases from $S_{2}^{*}$ to $S_{2}^{\prime}$, there will be oversupply of equity. But this is in contradiction with the assumption that $V_{2}^{\prime}>V^{*}$ is also an equilibrium. The case $V_{2}^{\prime}<V^{*}$ can be proved similarly.

Two features of the above model are worth noticing. First, no assumptions are made about investors' initial wealth. This is particularly helpful when conducting laboratory experiments because it reduces effects of sample selection on results. Second, except for the basic assumption that investors prefer more to less, no strong assumptions are made with respect to the shape of the utility function. Therefore, we expect experimental results based upon the above model to hold in fairly broad circumstances.

\section{Experimental protocol}

The computerized experiment was conducted in September 2007. Overall, we ran 3 sessions with a total of 78 participants, all being students at the Friedrich-Schiller University of Jena (Germany). The first session (with 14 participants) was performed in the video lab of the Max Planck Institute of Economics. In this session, two subjects were put into one cubicle and acted as one agent. ${ }^{6}$ We explicitly asked the participants to discuss loudly their strategy so that both their discussion and their game play could be recorded. The other two sessions (with 32 participants each) were run

\footnotetext{
${ }^{5}$ Since the optimal income streams of the two economies are the same in all states of the world, there is no need to have a specific utility function and to explicitly compute investors' expected utility.

${ }^{6}$ As only 14 subjects showed up, in two cubicles we had only one student.
} 
in the computer lab of the Max Planck Institute of Economics. The experiment was programmed in z-Tree (Fischbacher 2007). Considering the complexity of the experimental procedures, only students with relatively high analytical skills were invited, i.e., students majoring in subjects such as mathematics, physics, engineering, economics, and business administration.

Each experimental session had two subsequent phases. The first phase was used to measure participants' risk attitudes by means of Holt and Laury (2002) lottery task. The second phase was devoted to testing the model outlined in Sect. 2.2. ${ }^{7}$ The instructions distributed at the beginning informed participants that the experiment consisted of two phases, and explained the rules of the first phase only. Written instructions on the second phase were distributed at the end of the first one (a translation of instructions is provided in the supplement). In both phases amounts were denominated in ECU (Experimental Currency Units), where $10 \mathrm{ECU}=1$ Euro. Participants earned on average $€ 15$.90, inclusive of a $€ 2.50$ show-up fee.

\subsection{Measuring risk attitudes}

In the first phase, the lottery choice experiment developed by Holt and Laury (2002) is used to estimate participants' risk attitudes. ${ }^{8}$ Subjects are shown ten pairwise comparisons. In each comparison they are asked to choose between a safe option $Y$ and a risky option $X$ (see the instructions in the supplement for a complete representation of the ten comparisons). The payoff for option $Y$ is fixed at $50 \mathrm{ECU}$. The payoff for option $X$ can be either 70 ECU with probability $p$ or 30 ECU with probability $(1-p)$. In each successive comparison, $p$ increases by 10 percentage points, until finally the last decision involves no uncertainty. Subjects' choices (in particular, the comparison at which they switch from $Y$ to $X$ ) reveal their risk preferences. ${ }^{9}$ At the end of the phase, one of the ten comparisons is randomly selected to determine the payoff based upon the chosen option. In order not to effect choices in the following phase, feedback on individual earnings in the first phase is given only at the end of the session (i.e., on completion of the second phase).

\subsection{Testing the model}

The second phase provides data to test the MM theorem. To this aim, we rely on the model presented in Sect. 2.2. Participants are matched in groups of 8 (i.e., $N=8$ ) and asked to evaluate eight firms in eight successive treatments via a market mechanism to be explained shortly. In the experiment, treatments are referred to as rounds. Group composition does not change throughout the phase. ${ }^{10}$ Having one firm per treatment renders valuations independent from each other. To further discourage (po-

\footnotetext{
${ }^{7}$ Although the model does not depend on participants' risk attitudes, such attitudes can affect the firm's value in each single economy. Thus, assessing risk attitudes can provide valuable insights into the values of the firms implied by the data.

${ }^{8}$ While there is currently no agreement about how to best assess risk preferences, the Holt and Laury procedure offers several advantages, among which its easy applicability. Additionally, no systematic bias has been found with respect to alternative methods of measuring risk (see Harrison and Rutström 2008).

${ }^{9}$ Consistent subjects should only switch once from $Y$ to $X$, and never back from $X$ to $Y$.

${ }^{10} \mathrm{We}$ have, therefore, one group in the video lab session and four groups in each of the two computer lab sessions, yielding a total of nine groups.
} 
tential) portfolio effects, only one treatment/round is randomly selected for payment at the end of the experiment.

Denote a treatment by $T$ and the firm in the $T$-th treatment by $f_{T}$. Each $f_{T}$ is represented by a risky asset that generates income $\tilde{X}(\theta)$ that can be 1200 ECU or 800 ECU depending on whether $\theta$ (i.e., the state of the world) is good or bad, respectively.

Since our experimental design is rather complex (especially, the implemented market mechanism requires some cognitive effort), there is a need to minimize the impact of nuisance variables like fatigue, boredom, alertness, and computational skills. For this reason, we impose $\operatorname{Prob}(\theta=\operatorname{good})=\operatorname{Prob}(\theta=$ bad $)=\frac{1}{2}$. Equally likely outcomes are often encountered in practice and easy for subjects to understand. Additionally, some researchers argue that in the case of equally likely outcomes, probabilities are less subjectively weighted, i.e., they are less distorted (e.g., Quiggin 1982; Viscusi 1989), and-even if they are distorted - this distortion does not affect preferences (Levy and Levy 2002).

Each firm $f_{T}$ has 100 shares outstanding and a market value of bonds $B_{T}$, so that firms differ only in their value of $B_{T}$. Since there is no bankruptcy, bonds are perfectly safe: one unit of experimental money invested in bonds yields a gross return of 1.5, implying a net risk-free interest rate of 0.5 . The sequence of bonds' values $B_{T}$ chosen for characterizing the firms in the eight treatments is:

$$
\begin{aligned}
& \begin{array}{llllllll}
T: 1 & 2 & 3 & 4 & 5 & 6 & 7 & 8
\end{array} \\
& B_{T}: 50 \Rightarrow 350 \Rightarrow 100 \Rightarrow 0 \Rightarrow 400 \Rightarrow 200 \Rightarrow 500 \Rightarrow 300 \text {. }
\end{aligned}
$$

The first two treatments $(T=1,2)$ are for training purposes. Their sole aim is to familiarize the participants with the decision process and its incentives (they cannot be drawn for payment).

We preferred not to present subjects with the complete capital structure of each firm (income flow and bonds' market value). Instead, we give subjects the eight equities (that is, the resulting return structure after payment of the interest on the bonds: $\left.\tilde{X}-1.5 B_{T}\right)$ and ask them to evaluate each equity. Thus, the participants are confronted with the following sequence of risky alternatives:

$$
\begin{aligned}
& 1\left\{\begin{array} { l l } 
{ \text { Gain } } & { \text { Prob. } } \\
{ 1 1 . 2 5 } & { 0 . 5 } \\
{ 7 . 2 5 } & { 0 . 5 }
\end{array} \Rightarrow 2 \left\{\begin{array}{ll}
\text { Gain } & \text { Prob. } \\
6.75 & 0.5 \\
2.75 & 0.5
\end{array}\right.\right. \\
& \Rightarrow 3\left\{\begin{array} { l l } 
{ \text { Gain } } & { \text { Prob. } } \\
{ 1 0 . 5 0 } & { 0 . 5 } \\
{ 6 . 5 0 } & { 0 . 5 }
\end{array} \Rightarrow 4 \left\{\begin{array} { l l } 
{ \text { Gain } } & { \text { Prob. } } \\
{ 1 2 . 0 0 } & { 0 . 5 } \\
{ 8 . 0 0 } & { 0 . 5 }
\end{array} \Rightarrow 5 \left\{\begin{array}{ll}
\text { Gain } & \text { Prob. } \\
6.00 & 0.5 \\
2.00 & 0.5
\end{array}\right.\right.\right. \\
& \Rightarrow 6\left\{\begin{array} { l l } 
{ \text { Gain } } & { \text { Prob. } } \\
{ 9 . 0 0 } & { 0 . 5 } \\
{ 5 . 0 0 } & { 0 . 5 }
\end{array} \Rightarrow 7 \left\{\begin{array} { l l } 
{ \text { Gain } } & { \text { Prob. } } \\
{ 4 . 5 0 } & { 0 . 5 } \\
{ 0 . 5 0 } & { 0 . 5 }
\end{array} \Rightarrow 8 \left\{\begin{array}{ll}
\text { Gain } & \text { Prob. } \\
7.50 & 0.5 \\
3.50 & 0.5
\end{array}\right.\right.\right.
\end{aligned}
$$

A first reason for presenting each firm's equity as a 50/50 gamble is that some students (especially the economists) may have learned the MM theorem. Knowledge 
of the complete capital structure may induce them to be consistent with the theorem, thereby biasing the results. A second important reason is that such a presentation is very simple and allows us to effectively focus on the impact of different capital structures on the valuation of firms, minimizing any other confounding factor. If, in contradiction to the MM theorem, firms with different capital structures are evaluated differently, this pattern should emerge also when people are shown simple 50/50 gambles. To put it differently, if the theorem is violated in a complex environment, it is unclear whether the violation is due to the complexity of the task or is genuine in nature. On the other hand, if the MM theorem is not supported even in a simple setting like ours, we can more safely presume that there is something inherently wrong with the assumptions of the model.

It could be argued that given our presentation of the capital structure, compliance with the MM theorem is to be expected. ${ }^{11}$ Yet, despite our efforts to simplify the task, behaving in accordance with the theorem is not immediately straightforward. For example, instead of combining equities and bonds (thus making portfolio choices as suggested in the model) subjects could simplify the valuation process by ignoring their bond endowments and focusing exclusively on the valuation of equities. Additionally, subjects might not recognize the increase of systematic risk in equity until the leverage ratio reaches a certain threshold. In Davenport (1971), it is observed that there are substantial cost advantages to be gained by increasing leverage up to a certain range, and that there is also strong evidence that beyond a certain point further increases in the leverage ratio will lead to increases in the over-all cost of capital.

\subsubsection{Specific procedures and trading mechanism}

We now turn to a discussion of the specific procedures followed in the conduct of the second experimental phase.

At the beginning of each treatment/round $T(=1, \ldots, 8)$, four out of the eight group members receive 12 units of $T$ 's risky alternative (i.e., $12 \%$ of firm $f_{T}$ 's 100 shares) and an amount of ECU equal to $12 \%$ of $B_{T}$; the remaining four group members receive 13 units of $T$ 's risky alternative and an amount of ECU equal to $13 \%$ of $B_{T} \cdot{ }^{12}$ Participants are informed that their experimental money is automatically deposited into a bank, paying a net risk-free interest rate of 0.5 . Participants also know that they can borrow any amount of ECU from the bank at the same interest rate. The task of each subject is to trade the units of $T$ 's risky alternative at his disposal with the other seven members of his group. Traded quantities are required to be integers,

\footnotetext{
${ }^{11}$ For instance, Dell' Ariccia and Marquez (2010) show that when all liabilities are correctly priced, the MM irrelevance result applies to banks' organizational structure.

${ }^{12}$ The determination of the subjects' initial endowments is important, especially when subjects' payments are based on the net profits they make, as it is here. Since the theoretical model suggests that agents' endowments in the different treatments should be the same (cf., Eq. (3)), endowing the participants with the same amount of ECU might seem a natural choice. However, in a general equilibrium framework, endowing the participants with the same amount of ECU would require knowing the value of the firm a priori, i.e., before the experiment.
} 
and short selling is not allowed. Buying and selling prices must be within the range $\left[\left(800-1.5 \times B_{T}\right) /(100 \times 1.5),\left(1200-1.5 \times B_{T}\right) / 100\right] .^{13}$

Although the theoretical model is silent about the market trading mechanism, the experimental choice of it is very important. Since we are interested in equilibrium outcomes, the trading mechanism should allow for sufficient learning and convergence. Moreover, it should be able to effectively aggregate private information (e.g., one's own valuation of the alternatives), and to minimize the impact of individual mistakes on market prices.

In security markets, the daily opening price of a stock is especially difficult to determine because of the high uncertainty associated with the stock's fundamental value after the overnight non-trading period. To set a reliable opening price, most major stock exchanges (e.g., New York, London, Frankfurt, Paris) use a call auction to open markets. Economides and Schwartz (1995) show that, by gathering many orders together, the call auction can facilitate order entry, reduce volatility, and enhance price discovery. These features make the call auction a perfect candidate for our market experiment. ${ }^{14}$

More specifically, in each treatment/round the participants have 3 minutes to submit buy or sell orders. They must specify (a) how many units of the risky alternative they want to buy or sell, and (b) the price at which they wish to trade each unit. After the 3 minutes, aggregate demand and supply schedules are derived from the individual orders. The market clearing (equilibrium) price is chosen to maximize volume of trades. The algorithm used to compute the market clearing price is reproduced in Appendix A.

To help subjects set a "reasonable" price and to increase learning, the 3 minutes are divided into three trading periods, each lasting 1 minute. ${ }^{15}$ An "indicative" market clearing price is computed and announced at the end of the first two trading periods. This price is indicative in the sense that it suggests the price at which all eligible trades would occur if no orders were changed. Subjects know that they can revise their trade orders until the end of the allotted three minutes.

When the market closes, the net change in each agent's endowment of the risky alternative is considered. If the change is positive, for each purchased unit the agent pays a per-unit price equal to the market-clearing price; this amount is automatically deducted from the ECU he owns. If the change is negative, for each sold unit the agent receives a per-unit price equal to the market-clearing price; the received amount is automatically deposited in the bank, thereby earning a net risk-free interest rate of 0.5. To provide subjects with strong marginal incentive and to increase the cost of mistakes, we pay them only the net profits they make (the difference between the value of their final bundle and the value of their initial bundle).

\footnotetext{
${ }^{13}$ Notice that the upper bound of the interval allows for non-rational behavior (as a further check on subjects' understanding of the situation).

${ }^{14}$ An alternative is the double-auction mechanism, which has quicker and more efficient convergence properties (see, e.g., Smith et al. 1982; Cason and Friedman 1997, 2008; Kagel 2004), but is slower to implement and quite time consuming.

${ }^{15}$ To allow for sufficient learning, in each of the two training treatments the call auction opens for 6 minutes, and each trading period lasts 2 minutes.
} 
At the end of each $T$, subjects are informed about (a) the market clearing price, and (b) their own final holdings of ECU and risky alternative. To decrease income or wealth effects, information about the realized state of the world in each $T$ is given only at the end of the experiment, ${ }^{16}$ together with one's own net profit in each $T$, the treatment randomly chosen for payment, and one's own final payoff.

\subsection{A (control) individual decision-making experiment}

Testing the MM theorem via the above trading mechanism can provide helpful insights into how the market evaluates firms with different capital structures. However, for the model to hold, the markets must be always in equilibrium. As remarked above, previous experimental studies have cast doubt on the ability of call markets to produce convergence to the competitive equilibrium quickly and efficiently (see Cason and Friedman 1997, 2008, and references therein). Furthermore, even if the aggregate market outcome provides support for the MM theorem, this does not necessarily imply that every agent is making his utility-maximizing choice. Thus, following the suggestion of an anonymous referee, as a check on the robustness of our results, we ran a fourth session where 32 subjects participated in an individual decision-making experiment.

The session was conducted in the experimental laboratory of the Max Planck Institute. In accordance with the market experiment, only subjects with relatively high analytical skill were invited. Before starting the experiment, subjects had to answer three control questions. The session lasted about two hours including instructions and control questionnaire. The average payment was $€ 17.90$.

This control experiment maintains several features of the market experiment. Subjects play eight rounds, denoted once more by $T$. In each round $T$ subjects are presented with one of the risky alternatives given in (7), thereby facing a firm with a specific capital structure. Half of the subjects are endowed with 12 shares of firm $f_{T}$ and $12 \% \times B_{T}$ ECU; the other half of the subjects are endowed with 13 shares of firm $f_{T}$ and $13 \% \times B_{T}$ ECU. ${ }^{17}$ The experimental money is deposited into a bank, which pays a net interest rate of 0.5 for each ECU deposited. Similarly, subjects need to pay a net interest rate of 0.5 per borrowed ECU.

In each round (and thus for a given capital structure and endowment), four points on each subject's supply and demand curves for shares are elicited, corresponding to quantities of $1,5,9,12$ or 13. Specifically, a subject who is endowed with 12 (13) shares is asked to buy and sell 1, 5, 9, and 12 (13) units. In each round, the eight choices are elicited in a random order so as to exclude ordering effects.

As elicitation procedure we use the incentive-compatible Becker-DeGrootMarschak mechanism (Becker et al. 1964). In the four 'buy' decisions, each subject is asked to report the highest price $\operatorname{WTP}(x)(x=1,5,9,12$ or 13) at which he would be willing to buy each of the $x$ units, where $\operatorname{WTP}(x) \in[0.50,12]$. In the four 'sell' decision, each subject is asked to submit the minimum selling price WTA $(x)$ per unit,

\footnotetext{
${ }^{16}$ We provide this information at the end of $T=1,2$ (the two training treatments) to foster learning of the incentives.

${ }^{17}$ Shares are referred to as units of the risky alternative in the instructions.
} 
where $\operatorname{WTA}(x) \in[0.50,12]$. At the end of each round, one of the eight decisions is randomly selected. A further draw from a uniform distribution determines a random number $\pi \in[0.50,12]$ and the selected decision (either buy or sell) is executed depending on whether or not $\pi$ exceeds the price specified by the subject. ${ }^{18}$

\section{Experimental results}

The results are presented in two subsections. First, we analyze the data gathered from the market experiment, beginning with a presentation of the participants' risk attitudes. Then, as a robustness check, we detail the results of the individual decisionmaking experiment.

\subsection{Market experiment}

Risk attitudes play an important role in markets. In fact, in the current framework, heterogeneity of risk preferences is one of the main reasons for trading. In Holt and Laury (2002) lottery choice procedure - that we employed in the first phase of the market experiment - the subjects' total number of safe choices can be used as a proxy for risk aversion. Denote this proxy by $\gamma$. Obviously, the larger the value of $\gamma$, the higher the degree of risk aversion. We find considerable variation across people and a median $\gamma$-value of 6 , which suggests that most participants are risk averse. For example, for individuals who have Constant Relative Risk Aversion (CRRA) preferences with coefficient $\alpha$, a median $\gamma$-value of 6 corresponds to an $\alpha$ of 1.47. Furthermore, all subjects are consistent, i.e., they have a single switch point. ${ }^{19}$

According to standard portfolio theory, relatively risk averse individuals should hold a greater portion of their wealth in safe deposits, whereas more risk tolerant individuals should prefer higher-risk assets. In line with this assertion, we find that the correlation between $\gamma$ and subjects' end-holdings of experimental money is significantly positive (Spearman's $\rho=0.09, p<0.01$ ), and the correlation between $\gamma$ and subjects' end-holdings of the risky alternative is significantly negative (Spearman's $\rho=-0.091, p<0.05)$.

As noted above, given the complexity of our experiment, we invited only students with relatively high analytical skills. Moreover, prior to the experiment, subjects had to answer a control questionnaire testing their comprehension of the rules. We suspect, however, that some subjects did not pick up all facets of the problem. First, during the administration of the control questionnaire, a few people encountered difficulties in handling a gross interest rate of 1.5. Second, in the post-experimental questionnaire, a number of subjects explicitly complained about the difficulty of the task. It is then important to check that the experimental results are reliable. To this aim we compare the values of the firms implied by the experimental data with the theoretical values resulting from both the assumption of rational risk neutral agents

\footnotetext{
${ }^{18}$ If the payoff-relevant decision is a buy decision and $\mathrm{WTP}(x) \geq \pi$, the subject purchases the $x$ units at a unit price of $\pi$. If the payoff-relevant decision is a sell decision and WTA $(x) \leq \pi$, the subject sells the $x$ units at a unit price of $\pi$.

${ }^{19}$ Such a consistency may be a consequence of the stringent selection criteria used for recruiting subjects.
} 


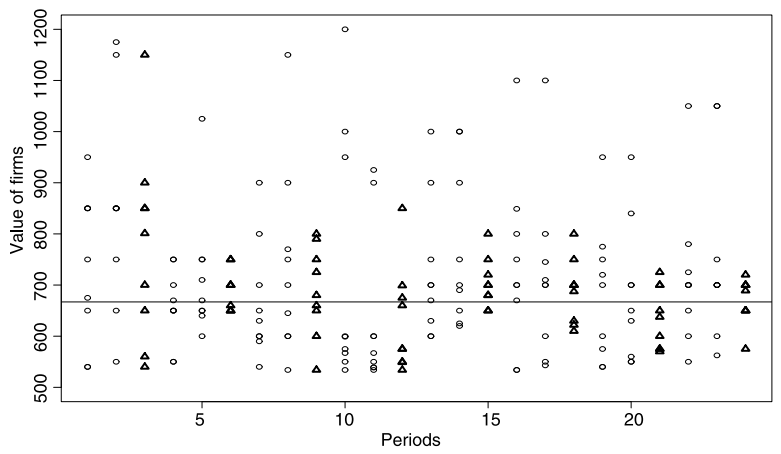

Fig. 1 Empirical values of the firms across periods

and the hypothesis that agents have CRRA utility function $u(w)=\frac{w^{1-1.47}}{1-1.47}$, where $\alpha=1.47$ is estimated from the observed median $\gamma$-value of $6 .^{20}$

Since the risk-free gross interest rate was 1.5 , a risky asset paying either 1200 or 800 with equal probabilities should be valued at $(1200 \times 0.5+800 \times 0.5) / 1.5=667$ by risk neutral rational agents. The valuation of firms by agents with CRRA utility function can be shown to be $628.07 .^{21}$ Figure 1 displays the development of the firms' empirical values across periods. On the horizontal axis, three consecutive periods represent one treatment, i.e., periods $1-3$ correspond to $T=1$, periods $4-6$ correspond to $T=2$, etc. The circles denote the firms' indicative values, calculated from the indicative market clearing prices determined at the end of the first two trading periods of each treatment. The triangles denote the firms' final values, calculated from the final market clearing prices determined in the third and last trading period of each treatment.

The median values of the firms are: 700 when all data points are used, 677.5 when the indicative prices are excluded from the sample, and 667.5 when both indicative prices and training periods are excluded. Wilcoxon signed-rank tests indicate that the central tendency of each of the three empirical distributions does not differ from 667 and 628.07 (lowest $p$-value $=0.47$ ).

We also observe that enough trading takes place at prices that are close to the mean of the three market-clearing prices determined in each treatment. Let $\bar{P}_{T}^{*}$ denote this mean. On average, in each treatment, groups buy 23.5 units and sell 26.83 units at prices falling in the interval $\left[\bar{P}_{T}^{*}-2, \bar{P}_{T}^{*}+2\right]$. Therefore, in spite of the complexity of the experimental procedures and the difficulty of the task, subjects perform surprisingly well and the results are reasonable.

Figure 1 shows that circles are more volatile than triangles, especially in the last treatments. This is not surprising because the markets in the first two trading periods are not yet mature (subjects get more adept as time passes), and because the indicative prices are not binding. Consequently, the following analysis shall consider only the

\footnotetext{
${ }^{20}$ The empirical value of a firm is obtained by adding the elicited market value of equity and the market value of bonds.

${ }^{21}$ See Appendix B for the calculation of this value.
} 
final market clearing prices and the six payoff-relevant treatments, unless otherwise stated.

A valid concern here is that subjects may have an aversion to borrow experimental money. Accordingly, the lower their initial endowment of ECU, the less units of shares they would buy. This, of course, would make the market values of the firms dependent on the people's money endowment. In order to test for this possibility, we perform the following analysis. For each independent group, we calculate the average value of the firms when $B_{T} \leq 200$ (denoted by $\bar{V}_{B \leq 200}$ ), and the average value of the firms when $B_{T} \geq 300$ (denoted by $\bar{V}_{B \geq 300}$ ). A two-sided Wilcoxon signed rank test

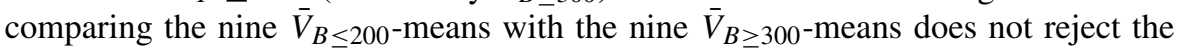
null hypothesis of equality of the two series $(p=0.26)$. We can therefore conclude that subjects' money endowment does not significantly affect the firms' value.

We conclude this subsection by noticing that not only Proposition 1 is the result of individual maximization, it also imposes a strong condition on individual portfolios. In particular, the proposition implies that individuals' holdings of equity should be the same under the different capital structures. An ANOVA analysis of individual shareholdings across the different capital structures cannot reject this hypothesis $(p>0.10)$.

\subsubsection{The effect of leverage on the cost of capital}

We now turn to our main research question and examine the empirical relationship between cost of capital and value of the firm derived from our data. As outlined in Sect. 2, there are two main competing views on this relationship. The first, the MM theorem, holds that the value of the firm is independent of its capital structure. The second is that the relationship is U-shaped: the weighted average cost of capital first decreases with the value of bonds and then increases. In the following, we shall compare these two views and see which best organizes the data.

Figure 2 reports the average values of the firms as a function of the values of the bonds, with average over the 9 independent groups. Since group heterogeneities may blur the picture, the same relationship is presented in Fig. 3 for the 9 groups

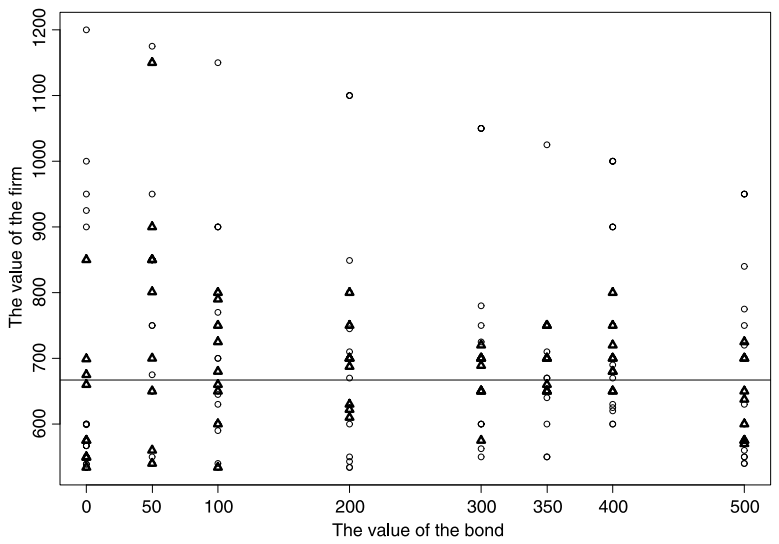

Fig. 2 Average values of the firms conditional on the market value of the bonds 

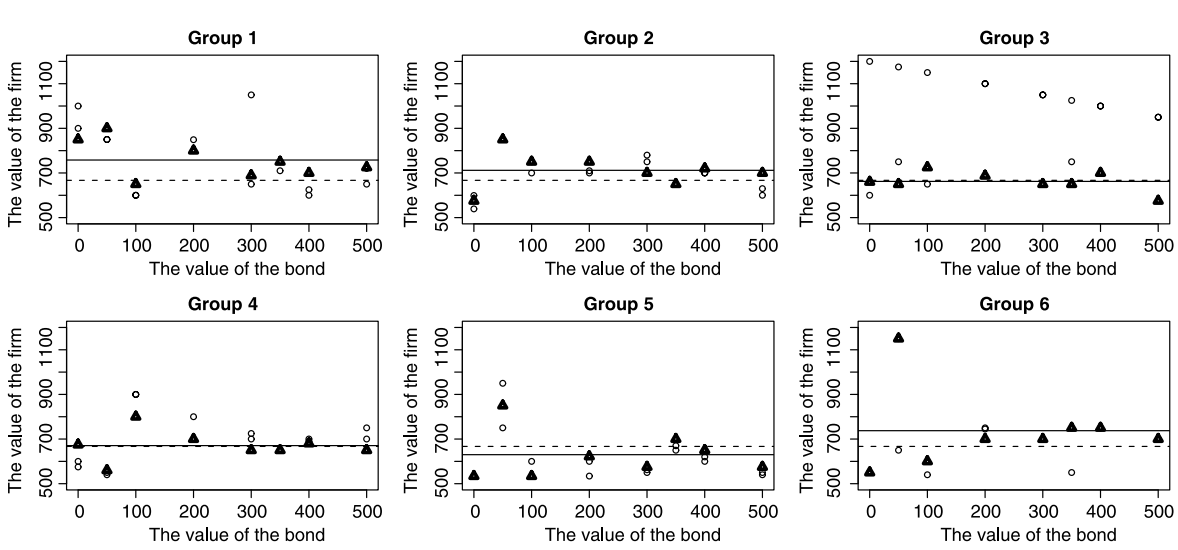

Group 7
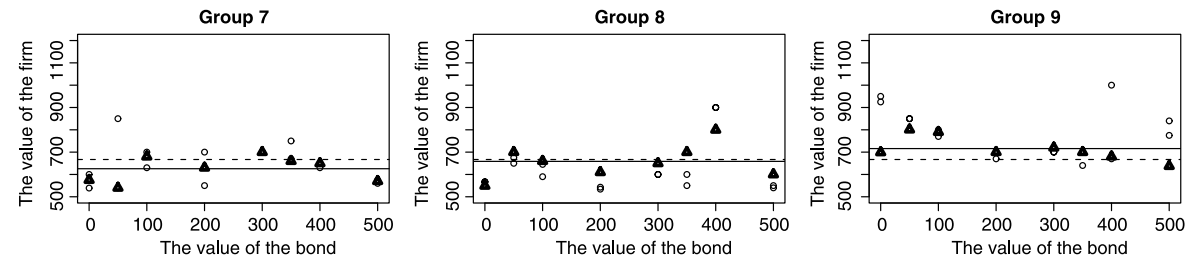

Fig. 3 Values of the firms conditional on the market value of the bonds, separately for each of the 9 independent groups

separately. To give a more general account of the data, both indicative values (circles) and final values (triangles) are illustrated. The continuous line in each panel of Fig. 3 denotes the group mean value of the firms, computed using only final market clearing prices.

The MM theorem suggests that any increase in leverage leads to an increase in the systematic risk of equity, which in turn leads the shareholders to demand higher returns. How well could subjects recognize changes in systematic risk due to changes in the capital structure? To address this issue, we compute the correlation between the value of equity and the value of bonds. Consistent with the MM theorem, we find that this correlation is negative and close to unity (Spearman's $\rho=-0.93, p<0.01$ ).

To examine the relationship between the value of the firm and the value of the bonds more precisely, we run two linear mixed-effects regressions. The first regression models the market values of the firms as a linear function of the value of the bonds $\left(B_{T}\right)$, the square of the value of the bonds $\left(B_{T}^{2}\right)$, and period $(t)$. Formally:

$$
V_{i}=v+u_{i}+\beta_{1} \cdot B_{T}+\beta_{2} \cdot B_{T}^{2}+\beta_{3} \cdot t+\varepsilon_{i},
$$

where $i \in\{1,2, \ldots, 9\}$ denotes the 9 independent groups, $u_{i} \backsim N\left(0, \sigma_{u}^{2}\right)$ denotes the random effects in the intercept for each group, and $\varepsilon_{i} \backsim N\left(0, \sigma_{e}^{2}\right)$.

The results (presented in Table 1) reveal that the coefficients of both $B_{T}$ and $B_{T}^{2}$ are statistically significant. Moreover, their signs are indicative of a U-shaped cost of capital curve. The coefficient of $t$ is weakly significant, suggesting that some kind of learning is taking place.

In the second regression, the dependent variable is the weighted average cost of capital (WACC), calculated as the expected return of the firm (i.e., 1000) divided 
Table 1 Regression results on the market values of the firms

${ }^{\text {a }}$ Significant at the $1 \%$ level

${ }^{\mathrm{b}}$ Significant at the $10 \%$ level

Table 2 Regression results on the weighted average cost of capital

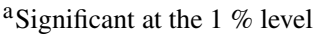

\begin{tabular}{lrrrr}
\hline Expl. variable & Coefficient & Std. error & $t$-statistic & $p$-value \\
\hline$v$ & $677.4643^{\mathrm{a}}$ & 30.6054 & 22.1354 & 0.0000 \\
$B_{T}$ & $0.6457^{\mathrm{a}}$ & 0.1902 & 3.3956 & 0.0015 \\
$B_{T}^{2}$ & $-0.0011^{\mathrm{a}}$ & 0.0003 & -3.2616 & 0.0022 \\
$t$ & $-4.2244^{\mathrm{b}}$ & 2.1541 & -1.9611 & 0.0565 \\
\hline Std. dev. of the random effects & $\sigma_{u}=38.8864$ & \\
Std. dev. of error term & $\sigma_{e}=58.0902$ & \\
Number of observations & 54 & & \\
\hline
\end{tabular}

\begin{tabular}{lclrl}
\hline Expl. variable & Coefficient & Std. error & $t$-statistic & $p$-value \\
\hline$\kappa$ & $1.5305^{\mathrm{a}}$ & 0.0674 & 22.7151 & 0.0000 \\
$\tau$ & $-0.9702^{\mathrm{a}}$ & 0.2453 & -3.9546 & 0.0003 \\
$\tau^{2}$ & $1.0941^{\mathrm{a}}$ & 0.2642 & 4.1418 & 0.0002 \\
$t$ & 0.0069 & 0.0047 & 1.4620 & 0.1512 \\
\hline Std. dev. of the random effects & $\sigma_{u}=0.0886$ & \\
Std. dev. of error term & $\sigma_{e}=0.1262$ & \\
Number of observations & 54 & & \\
\hline
\end{tabular}

by the market value of the firm. Independent variables are the leverage ratio $(\tau)$, measured as the market value of the bonds divided by the market value of the firm, the leverage ratio squared $\left(\tau^{2}\right)$, and period $(t)$. The formal equation is similar to (8), and the estimated equation turns out as follows (see Table 2):

$$
\mathrm{WACC}=1.5305-0.9702 \cdot \tau+1.0941 \cdot \tau^{2},
$$

which offers further support for the U-shaped cost of capital approach.

\subsection{Individual decision-making experiment}

In this section, we present the results of the control experiment where valuations are defined as reservation prices that a person is either willing to pay (WTP) to purchase $x$ units or willing to accept (WTA) to forgo $x$ units. Table 3 provides average valuations, separately for the type of trade, the eight bonds' values, and the four traded quantities.

One thing which stands out immediately is that WTP is generally lower than WTA. The difference is significant not only when we average over all four traded quantities ( $p<0.01$, paired Wilcoxon test), but also when we consider the four feasible quantities separately ( $p<0.05$ for all four one-sided paired Wilcoxon tests). Additionally, the difference between WTP and WTA is larger, the more units need to be traded (on average: -131.46 for $x=1$; -199.78 for $x=5$; -260.91 for $x=9$; -299.08 for $x=12,13$ ). In the last four decades, numerous studies have provided evidence of a WTP-WTA gap (for reviews, see Horowitz and McConnell 2002; 
Table 3 Mean valuations for each value of bonds and each traded quantity, separately for buy and sell decisions

\begin{tabular}{|c|c|c|c|c|c|c|c|c|}
\hline \multirow{2}{*}{$\begin{array}{l}\text { Bonds } \\
\text { value }\end{array}$} & \multicolumn{4}{|c|}{ Buy decisions (WTP) } & \multicolumn{4}{|c|}{ Sell decisions (WTA) } \\
\hline & 1 unit & 5 units & 9 units & 12,13 units & 1 unit & 5 units & 9 units & 12,13 units \\
\hline 0 & 775.19 & 657.53 & 640.41 & 640.22 & 848.81 & 842.91 & 861.06 & 815.19 \\
\hline 50 & 765.03 & 609.16 & 560.62 & 575.81 & 883.16 & 825.91 & 852.41 & 916.72 \\
\hline 100 & 687.22 & 648.06 & 606.34 & 624.28 & 825.31 & 867.44 & 814.25 & 825.72 \\
\hline 200 & 734.81 & 609.25 & 580.62 & 499.59 & 814.06 & 840.69 & 847.25 & 878.41 \\
\hline 300 & 684.09 & 618.75 & 539.22 & 541.12 & 915.31 & 839.56 & 885.16 & 905.78 \\
\hline 350 & 727.03 & 639.41 & 654.12 & 595.69 & 875.69 & 848.84 & 855.97 & 867.94 \\
\hline 400 & 661.88 & 687.69 & 621.69 & 543.94 & 831.25 & 824.00 & 851.12 & 879.81 \\
\hline 500 & 726.94 & 657.75 & 555.47 & 515.88 & 820.25 & 836.50 & 878.53 & 839.59 \\
\hline All & 720.27 & 640.95 & 594.81 & 567.07 & 851.73 & 840.73 & 855.72 & 866.14 \\
\hline
\end{tabular}

Sayman and Öncüler 2005). The studies draw on a wide range of goods including ordinary private goods (such as chocolates, pens, and mugs), non-market goods (such as food safety), and lotteries. ${ }^{22}$ To the best of our knowledge, we are the first to document the WTP-WTA gap with intangible assets in a lab experiment.

Participants' endowment of experimental money varies from round to round, and the ECU at their disposal may affect willingness to pay. It is therefore worthy to investigate whether buy decisions vary with the ECU endowment. To this aim, we perform an analysis similar to the one done for the market experiment. We compute, for each $x$ and each subject, the average $\operatorname{WTP}(x)$ separately for $B_{T} \leq 200$ and $B_{T} \geq$ 300. Comparing the 32 individual average $\operatorname{WTP}(x)$ when $B_{T} \leq 200$ and when $B_{T} \geq$ 300 , it is not possible to reject the null hypothesis that, for each $x$, the two series have identical distributions ( $p>0.10$ for all four traded quantities, two-sided Wilcoxon signed rank tests). This suggests that subjects' willingness to pay is not influenced by the size of the ECU endowment.

The utility maximization assumption in Proposition 1 (Eq. 6) implies that if all shares were owned by individuals identical to a certain subject, the value of the firm resulting from the price reported for a given quantity should be the same across all capital structures. That is, if we denote by $V_{f_{\tau^{\prime}}}(x)$ and $V_{f_{\tau^{*}}}(x)$ the value of the firms with capital structure, respectively, $\tau^{\prime}$ and $\tau^{*}$ when $x$ shares are traded, the proposition requires that for each $x: V_{f_{\tau^{\prime}}}(x)=V_{f_{\tau} *}(x)$ for all $\tau^{\prime}, \tau^{*}=1,2, \ldots, 8$, and $\tau^{\prime} \neq \tau^{*}$.

To test this assumption, for each $x$ we compare-via a series of Wilcoxon signedrank tests-the observed valuations of the 32 subjects across the eight capital structures. For each $x$ we therefore perform 28 comparisons (namely, $\left.\frac{8 !}{2 !(8-2) !}\right) \cdot{ }^{23}$ With

\footnotetext{
${ }^{22}$ See Plott and Zeiler (2005) and Isoni et al. (2011) for a brief account of these experiments and their results.

${ }^{23}$ An alternative way to test the assumption would be to examine, for each individual, how similar his 8 valuations are across the 4 traded quantities. We preferred our approach because of its greater statistical power: we compare two series, each of which consists of 32-rather than 8-data points.
} 
four traded quantities, we have $28 \times 4=112$ comparisons for the buy decisions and 112 comparisons for the sell decisions. Using $p<0.05$ as the significance level, a significant difference is detected for $5.35 \%$ (6 out of 112) comparisons in the buy decisions, and for $2.68 \%$ ( 3 out of 112) comparisons in the sell decisions. ${ }^{24}$ Thus, overall, we do not find strong evidence against the utility maximization assumption implied by Proposition 1.

Finally, we run a linear regression with mixed effects to explore carefully the impact of bonds on the valuation of the firms. Explanatory variables are the intercept $(v)$, the bonds' value $\left(B_{T}\right)$, the square of the bonds' value $\left(B_{T}^{2}\right)$, the dummy Trade $_{s}$ (which equals 0 for the WTP and 1 for the WTA), the four traded quantities $(x 1, x 5$, $x 9$, and $x 123$ ), and the interaction between traded quantity and type of trade. Random effects are the 32 individual subjects. Formally, the model is as follows:

$$
\begin{aligned}
V_{i}= & v+u_{i}+\beta_{1} \cdot B_{T}+\beta_{2} \cdot B_{T}^{2}+\beta_{3} \cdot \operatorname{Trade}_{s}+\beta_{4} \cdot x 5+\beta_{5} \cdot x 9 \\
& +\beta_{6} \cdot x 123+\beta_{7} \cdot \operatorname{Trade}_{s} \cdot x 5+\beta_{8} \cdot \operatorname{Trade}_{s} \cdot x 9 \\
& +\beta_{9} \cdot \operatorname{Trade}_{s} \cdot x 9+\beta_{10} \cdot \operatorname{Trade}_{s} \cdot x 123+\varepsilon_{i},
\end{aligned}
$$

where $i \in\{1,2, \ldots, 32\}$ denotes the 32 subjects, $u_{i} \backsim N\left(0, \sigma_{u}^{2}\right)$ denotes the random effects in the intercept for each subject, and $\varepsilon_{i} \backsim N\left(0, \sigma_{e}^{2}\right)$. The results of the regression are presented in Table 4.

The coefficients of both $B_{T}$ and $B_{T}^{2}$ are not significant (i.e., bonds have no effect on the valuation of firms), which agrees with the MM theorem rather than with the U-shaped cost of capital approach. This result is not consistent with the one obtained from the market experiment. We have no clear-cut answer to the reason for this discrepancy. However, we suspect that it may be related to the large difference in the

Table 4 Regression results on reservation prices

${ }^{\text {a }}$ Significant at the $1 \%$ level

\begin{tabular}{lcrrr}
\hline Expl. variable & Coefficient & Std. error & $t$-statistic & $p$-value \\
\hline$v$ & $729.7523^{\mathrm{a}}$ & 25.6347 & 28.4674 & 0.0000 \\
$B_{T}$ & -0.0681 & 0.1166 & -0.5840 & 0.5593 \\
$B_{T}^{2}$ & 0.0001 & 0.0002 & 0.3405 & 0.7335 \\
Trade $_{s}$ & $131.4570^{\mathrm{a}}$ & 21.2012 & 6.2004 & 0.0000 \\
$x 5$ & $-79.3242^{\mathrm{a}}$ & 21.2012 & -3.7415 & 0.0002 \\
$x 9$ & $-125.4609^{\mathrm{a}}$ & 21.2012 & -5.9176 & 0.0000 \\
$x 123$ & $-153.2070^{\mathrm{a}}$ & 21.2012 & -7.2263 & 0.0000 \\
Trade $_{s} \times x 5$ & $68.3242^{\mathrm{a}}$ & 29.9830 & 2.2788 & 0.0228 \\
Trade $_{s} \times x 9$ & $129.4492^{\mathrm{a}}$ & 29.9830 & 4.3174 & 0.0000 \\
Trade $_{s} \times x 123$ & $167.6211^{\mathrm{a}}$ & 29.9830 & 5.5905 & 0.0000 \\
\hline Std. dev. of the random effects $^{2} \sigma_{u}=102.2934$ & \\
Std. dev. of error term $^{2}$ & $\sigma_{e}=239.8642$ & \\
Number of observations $^{2} 2048$ & & \\
\hline
\end{tabular}

${ }^{24}$ All significant differences are observed when the subjects trade the maximum quantity of shares $(x=12$ or 13). 
standard deviation of the error terms in the two conditions: 239.8642 for the individual decision-making experiment vs. 58.0902 for the market experiment. The larger standard deviation of the error terms in the individual decision-making experiment suggests that participants' decisions are noisier in this environment. The remaining estimated coefficients confirm the results discussed above: (a) WTA exceed WTP (the coefficient of Trade $_{s}$ is positive and significant), and (b) the more units need to be traded, the lower the WTP and the higher the WTA.

With each subject's demand and supply points in hand, we could create artificial markets and compute the value of the firms from the market clearing price of these artificial markets. Yet, due to the huge difference between WTP and WTA, no market clearing price exists in most artificial markets. Note the marked contrast between this result and the one of the market experiment. When valuations result from a market institution, many trades take place around the reservation price of 667 . The finding that the market more closely matches rational choice theory is in line with past literature indicating that exchange institutions "serve to push behavior more toward the Homo Economicus fiction we assume in our models" (Shogren and Taylor 2008, p. 34). ${ }^{25}$

\section{Conclusions}

When the leverage of a firm increases, the systematic risk of the firm's equity increases as well. Modigliani and Miller (1958) show that the higher return demanded by equity holders exactly offsets the lower market value of the bonds and, as a result, the weighted average cost of capital remains the same. This paper is a first attempt to investigate the Modigliani-Miller theorem in laboratory markets where agents can trade shares of firms generating the same income stream via different capital structures. The design includes some features intended to give the theorem its "best shot" at organizing the data. Additionally, we performed a control individual decision-making experiment where we elicited several points on the individual supply and demand curves for shares.

The results identify some strengths and some weaknesses of Modigliani and Miller's approach. On the one hand, subjects recognize the increased systematic risk of equity when leverage increases, and thus demand a higher return for bearing this risk. On the other hand, the regression results are supportive of a U-shaped cost of capital curve, suggesting that subjects tend to underestimate the riskiness of lowleveraged equity and to overestimate the riskiness of high-leveraged equity.

We do not regard our results as a behavioral rejection of the main proposition of the MM theorem. First, its main proposition does a good job of organizing the data in the control experiment. Second, some of its hypotheses cannot be rejected in the market experiment as well. The lack of full support for the theorem may be due to market "imperfections", defined as anything that interferes with trade, therefore causing a rational market participant either to deviate from holding the market portfolio or to

\footnotetext{
${ }^{25} \mathrm{Chu}$ and $\mathrm{Chu}$ (1990) show that the incidence of preference reversals is reduced in a market-like environment. Brocas and Carrillo (2001) find that direct competition alleviates inefficiencies due to time inconsistency.
} 
depart from his preferred risk level (see, e.g., DeGennaro 2005). For instance, the use of a single call market and the exclusion of arbitrage opportunities could have affected our findings. Understanding whether these design choices are important or the violation of the theorem is genuine in nature may provide a fruitful avenue for future research.

Open Access This article is distributed under the terms of the Creative Commons Attribution License which permits any use, distribution, and reproduction in any medium, provided the original author(s) and the source are credited.

\section{Appendix A: Algorithm to compute the market clearing price in the call auction}

The following algorithm was used to calculate the market clearing price:

1. Any order for buying $Q$ units at price $P_{b}$ is transformed into a vector where $P_{b}$ is repeated $Q$ times, so that each element of this vector can then be treated as a single buy order at price $P_{b}$. The individual vectors are then combined into a general buy vector, which is sorted by buying price in descending order (from highest to lowest). A similar operation is done for all sell orders except that the resulting vector is sorted by selling price from lowest to highest. In this way, aggregate demand and supply schedules are constructed:

$$
\begin{array}{ll}
\text { The buy vector } & \left(P_{b}^{1}, P_{b}^{2}, \ldots, P_{b}^{i}, P_{b}^{i+1}, \ldots, P_{b}^{\text {end }}\right), \\
\text { The sell vector } & \left(P_{s}^{1}, P_{s}^{1}, \ldots, P_{s}^{i}, P_{s}^{i+1}, \ldots, P_{s}^{\text {end }}\right),
\end{array}
$$

where $P_{b}^{i} \geq P_{b}^{i+1}$ and $P_{s}^{i} \leq P_{s}^{i+1}$.

2. These two vectors are then pairwise compared $\left(P_{b}^{i}\right.$ and $\left.P_{s}^{i}\right)$, and this searching process continues until a first pair $i$ where $P_{b}^{i}<P_{s}^{i}$ is found. Obviously, a market clearing price should satisfy

$$
P_{b}^{i}<P<P_{s}^{i},
$$

since these two orders should not be executed. Meanwhile, $P_{b}^{i-1}$ and $P_{s}^{i-1}$ should be exchangeable at the market clearing price, which implies

$$
P_{s}^{i-1}<P<P_{b}^{i-1}
$$

Combining these two conditions, the market clearing price should satisfy

$$
\max \left\{P_{s}^{i-1}, P_{b}^{i}\right\}<P^{*}<\min \left\{P_{b}^{i-1}, P_{s}^{i}\right\} .
$$

In the experiment, $P^{*}$ is set to be $\frac{\max \left\{P_{s}^{i-1}, P_{b}^{i}\right\}+\min \left\{P_{b}^{i-1}, P_{s}^{i}\right\}}{2}$.

3. If there is an excess demand or supply at this market clearing price, only the minimum quantity of the buy or sell orders is randomly selected for execution. 
4. It is possible that a market clearing price may not be found by this way if $P_{b}^{1}<P_{s}^{1}$ or $P_{b}^{\text {end }}>P_{s}^{\text {end }}$. In this case, $P_{s}^{1}-0.01$ is chosen to be the market clearing price if $P_{b}^{1}<P_{s}^{1}$, and $P_{b}^{\text {end }}+0.01$ is chosen to be the market clearing price if $P_{b}^{\text {end }}>$ $P_{S}^{\text {end }}$.

\section{Appendix B: Calculation of equilibrium value of firms when agents have CRRA utility function $u(w)=\frac{w^{1-1.47}}{1-1.47}$}

Although Proposition 1 concerns the comparison of firms' values in different economies and does not rely on a specific utility function, the market participants' risk attitudes can affect the value of a firm in each single economy. Here we provide an example to illustrate how the equilibrium value of a firm is determined when individuals have CRRA utility function $u(w)=\frac{w^{1-1.47}}{1-1.47}$.

Consider first the economy where the firm issues no bond $(B=0)$. There are 100 units of equity outstanding. Let $s$ denote the price per unit of equity, and $\bar{\alpha}$ be the initial endowment of an individual in the economy. Individuals with CRRA utility function in this economy maximize their utility by choosing the number of shares to hold $(\alpha)$ and the individual credit to borrow from the market at the interest rate of $1.5(b) .^{26}$

$$
\begin{aligned}
& \max _{\alpha, b} U(\alpha, b)=0.5 \cdot \frac{(12 \cdot \alpha+1.5 \cdot b)^{1-1.47}}{1-1.47}+0.5 \cdot \frac{(8 \cdot \alpha+1.5 \cdot b)^{1-1.47}}{1-1.47} \\
& \text { s.t. } \quad \alpha \cdot s+b=\bar{\alpha} \cdot s .
\end{aligned}
$$

Solving for $b$ from the budget constraint and replacing $b=(\bar{\alpha}-\alpha) \cdot s$ in the maximization equation, we have

$$
\begin{aligned}
\max _{\alpha} U(\alpha)= & 0.5 \cdot \frac{[12 \cdot \alpha+1.5 \cdot(\bar{\alpha}-\alpha) \cdot s]^{1-1.47}}{1-1.47} \\
& +0.5 \cdot \frac{(8 \cdot \alpha+1.5 \cdot(\bar{\alpha}-\alpha) \cdot s)^{1-1.47}}{1-1.47}
\end{aligned}
$$

The first order condition for the above maximization problem is

$$
\begin{aligned}
\frac{d U(\alpha)}{d \alpha}= & 0.5 \cdot(12-1.5 \cdot s) \cdot[12 \cdot \alpha+1.5 \cdot(\bar{\alpha}-\alpha) \cdot s]^{-1.47} \\
& +0.5 \cdot(8-1.5 \cdot s) \cdot[8 \cdot \alpha+1.5 \cdot(\bar{\alpha}-\alpha) \cdot s]^{-1.47} \\
= & 0
\end{aligned}
$$

which reduces to

$$
\left(\frac{1.5 \cdot s-8}{12-1.5 \cdot s}\right)^{-\frac{1}{1.47}}=\left[\frac{8 \cdot \alpha+1.5(\bar{\alpha}-\alpha) s}{12 \cdot \alpha+1.5(\bar{\alpha}-\alpha) s}\right] .
$$

\footnotetext{
${ }^{26}$ We drop the index for each individual since they are assumed to be the same.
} 
Setting $K=\left(\frac{1.5 \cdot s-8}{12-1.5 \cdot s}\right)^{-\frac{1}{1.47}}$, we have

$$
\alpha=\frac{1.5 \cdot \bar{\alpha} \cdot s-1.5 \cdot K \cdot \bar{\alpha} \cdot s}{12 \cdot K-1.5 \cdot K \cdot s-8+1.5 \cdot s} .
$$

Thus, individual demand for equity is a function of its price $s$. Being the economy closed, the market for equity should clear. Since all individuals have the same utility function, there will be no trade in equilibrium and every agent holds the initial amount of equity. In this equilibrium, the market clears when

$$
s=6.2807 \text {. }
$$

Here, we have assumed that the firm issues no bond. The equilibrium value of the firm is therefore $V=100 \times s=628.07$. Proposition 1 suggests that the same value should be obtained from economies with a different capital structure.

\section{References}

Arzac, E. R., \& Glosten, L. R. (2005). A reconsideration of tax shield valuation. European Financial Management, 11, 453-461.

Becker, G. M., DeGroot, M. H., \& Marschak, J. (1964). Measuring utility by a single-response sequential method. Systems Research and Behavioral Science, 9, 226-232.

Cason, T. N., \& Friedman, D. (1997). Price formation in single call markets. Econometrica, 65(2), 311345.

Cason, T. N., \& Friedman, D. (2008). A comparison of market institutions. In C. R. Plott \& V. L. Smith (Eds.), Handbook of experimental economics results (pp. 264-272). Amsterdam: North Holland.

Chu, Y.-P., \& Chu, R.-L. (1990). The subsidence of preference reversals in simplified and marketlike experimental settings: a note. American Economic Review, 80(4), 902-911.

Dann, L. Y. (1981). Common stock repurchases: an analysis of returns to bondholders and stockholders. Journal of Financial Economics, 9(2), 113-138.

Davenport, M. (1971). Leverage and the cost of capital: some tests using British data. Economica, 38(150), $136-162$.

DeGennaro, R. P. (2005). Market imperfections. Working paper series 2005-12, Federal Reserve Bank of Atlanta.

Dell'Ariccia, G., \& Marquez, R. (2010). Risk and the corporate structure of banks. The Journal of Finance, 65(3), 1075-1096.

Economides, N., \& Schwartz, R. A. (1995). Electronic call market trading. The Journal of Portfolio Management, 21, 10-18.

Fischbacher, U. (2007). Zurich toolbox for readymade economic experiments. Experimental Economics, 10(2), 171-178.

Graham, J. R., \& Harvey, C. R. (2001). The theory and practice of corporate finance: evidence from the field. Journal of Financial Economics, 60, 187-243.

Harrison, G., \& Rutström, E. (2008). Risk aversion in the laboratory. In J. Cox \& G. Harrison (Eds.), Risk aversion in experiments: Vol. 12. Research in experimental economics (pp. 41-196). Burlington: Emerald Group Publishing.

Horowitz, J. H., \& McConnell, K. E. (2002). A review of WTA/WTP studies. Journal of Environmental Economics and Management, 44, 426-447.

Hirshleifer, J. (1966). Investment decision under uncertainty: application of the state preference approach. Quarterly Journal of Economics, 80(2), 252-277.

Holt, C. A., \& Laury, S. K. (2002). Risk aversion and incentive effects in lottery choices. American Economic Review, 92, 1644-1655.

Isoni, A., Loomes, G., \& Sugden, R. (2011). The willingness to pay-willingness to accept gap, the "endowment effect", subject misconceptions, and experimental procedures for eliciting valuations: comment. American Economic Review, 101(2), 991-1011. 
Kagel, J. H. (2004). Double auction markets with stochastic supply and demand schedules: call markets and continuous auction trading mechanisms. In S. Huck (Ed.), Advances in understanding strategic behaviour: game theory, experiments, and bounded rationality. Essays in honour of Werner Güth (pp. 181-208). Basingstoke, UK: Palgrave Macmillan.

Levy, H., \& Levy, M. (2002). Experimental test of the prospect theory value function: a stochastic dominance approach. Organizational Behavior and Human Decision Processes, 89, 1058-1081.

Masulis, R. W. (1980). The effects of capital structure change on security prices: a study of exchange offers. Journal of Financial Economics, 8(2), 139-178.

Masulis, R. W., \& Korwar, A. N. (1986). Seasoned equity offerings: an empirical investigation. Journal of Financial Economics, 15(1/2), 91-118.

Miller, M. H., \& Modigliani, F. (1966). Some estimates of the cost of the capital to the electric utility industry, 1954-1957. American Economic Review, 56, 333-391.

Modigliani, F., \& Miller, M. H. (1958). The cost of capital, corporation finance and the theory of investment. American Economic Review, 48(3), 261-297.

Myers, S. C. (2001). Capital structure. Journal of Economic Perspectives, 15(2), 81-102.

Pinegar, J. M., \& Lease, R. C. (1986). The impact of preferred-for-common exchange offers on firm value. The Journal of Finance, 41(4), 795-814.

Plott, C. R., \& Zeiler, K. (2005). The willingness to pay-willingness to accept gap, the "endowment effect", subject misconceptions, and experimental procedures for eliciting valuations. American Economic Review, 95(3), 530-545.

Quiggin, J. (1982). A theory of anticipated utility. Journal of Economic Behavior \& Organization, 3, 323343.

Robichek, A. A., McDonald, J. G., \& Higgins, R. C. (1967). Some estimates of the cost of capital to electric utility industry, 1954-1957: comment. American Economic Review, 57, 1278-1288.

Sayman, S., \& Öncüler, A. (2005). Effects of study design characteristics on the WTA-WTP disparity: a meta analytical framework. Journal of Economic Psychology, 26, 289-312.

Shleifer, A., \& Vishny, R. W. (1997). The limits of arbitrage. The Journal of Finance, 52, 35-55.

Shogren, J. F., \& Taylor, L. O. (2008). On behavioral-environmental economics. Review of Environmental Economics and Policy, 2, 26-44.

Smith, V. L., Williams, A. W., Bratton, W. K., \& Vannoni, M. G. (1982). Competitive market institutions: double auctions vs. sealed bid-offer auctions. American Economic Review, 72(1), 58-77.

Stiglitz, J. E. (1969). A re-examination of the Modigliani-Miller theorem. American Economic Review, 59(5), 784-793.

Viscusi, W. K. (1989). Prospective reference theory: toward an explanation of the paradoxes. Journal of Risk and Uncertainty, 2(3), 235-264.

Weston, J. F. (1963). A test of capital propositions. Southern Economic Journal, 30, 105-112. 